\title{
Progression of Non-Culprit Coronary Artery Atherosclerosis After Acute Myocardial Infarction in Comparison with Stable Angina Pectoris
}

Satoshi Okayama, Shiro Uemura, Taku Nishida, Yoshinobu Morikawa, Kenji Onoue, Yasuhiro Takemoto, Tsunenari Soeda, Satoshi Somekawa, Ken-ichi Ishigami, Yukiji Takeda, Manabu Horii, Hiroyuki Kawata, Minoru Takaoka, Tamio Nakajima, and Yoshihiko Saito

First Department of Internal Medicine, Nara Medical University, Nara, Japan.

\begin{abstract}
Aim: We previously found, using a mouse model, that activation of proinflammatory cytokines after acute myocardial infarction (AMI) augments neointimal hyperplasia of a remote artery. The present study assessed the progression of luminal narrowing of non-culprit coronary arteries (NCCA) in patients following AMI.

Methods: The study group comprised 21 AMI patients successfully treated with bare-metal stents and 16 stable angina (SA) patients treated with sirolimus-eluting stents. Clinical backgrounds were similar for both groups. Quantitative coronary angiography was performed before and after stent implantation and at 6-months of follow-up.

Results: We evaluated 126 non-culprit coronary segments (73 in AMI and 53 in SA). The minimum lumen diameter (MLD) (mm) of NCCA decreased significantly from $2.61 \pm 0.79$ to $2.44 \pm 0.71$ in the AMI group, but changed only slightly from $2.02 \pm 0.56$ to $2.02 \pm 0.50$ in the SA group. The absolute change in the MLD of NCCA was significantly greater $(0.17 \pm 0.53)$ in the AMI, than in the SA $(0.0070 \pm 0.261)$ group.

Conclusion: luminal narrowing of non-culprit coronary segments progressed in AMI patients within 6 months of stent implantation, but progressed only slightly in SA patients.
\end{abstract}

J Atheroscler Thromb, 2008; 15:228-234.

Key words; Quantitative coronary angiography, Bare-metal stent, Sirolimus-eluting stent, Inflammation

\section{Introduction}

Percutaneous coronary intervention (PCI), first performed in $1968^{1)}$, has dramatically improved the outcome of treatment for coronary artery disease (CAD). Even conventional plain balloon angioplasty has significantly improved ischemia-related symptoms, but, periprocedural complications such as acute artery occlusion and chronic restenosis occur in approximately 5 and $40 \%$ of cases, respectively ${ }^{2-4}$. Bare-metal stent (BMS) implantation and ticlopidine administration

Address for correspondence: Shiro Uemura, First Department of Medicine, Nara Medical University 840 Shijo-cho, Kashihara, Nara 634-8522, Japan.

E-mail: suemur@naramed-u.ac.jp

Received: September 14, 2007

Accepted for publication: May 9, 2008 have significantly decreased acute procedural complications, but have been unable to prevent chronic instent restenosis ${ }^{5-8)}$. Sirolimus-eluting stent (SES) implantation significantly decreased the chronic in-stent restenosis rate to $5-7 \%$ through its anti-inflammatory effects, inhibiting several regulators of cell-cycle progression, and the migration of vascular smooth-muscle cells ${ }^{9,10)}$. Although SES implantation has the potential risk of late thrombosis after the stopping of antiplatelet therapy ${ }^{11,12)}$, treatment of the culprit coronary artery is nearly perfect. However, for further improvements of the long-term prognosis in CAD patients, it became apparent that an appropriate treatment strategy for non-culprit coronary arteries is critical.

The genetic background ${ }^{13)}$, pathophysiology ${ }^{14-18)}$, and prognosis ${ }^{19)}$ of AMI considerably differ from those of SA. AMI is more associated with an enhanced 
inflammatory response and vulnerable plaques than SA. Furthermore, subsequent coronary events including recurrent AMI and in-stent restenosis after PCI are more frequent in patients with AMI than with SA.

The plasma concentrations of various proinflammatory cytokines and growth factors, including tumor necrotic factor- $\alpha$ (TNF- $\alpha)$, interleukin- $\beta$ (IL-1 $\beta$ ), interleukin-6 (IL-6), vascular endothelial growth factor (VEGF), and hepatocyte growth factor (HGF) are significantly elevated for approximately 2 weeks after onset $^{20,21)}$ in the setting of AMI, but only slightly elevated in that of SA. We previously found, using a mouse model, that the activation of proinflammatory cytokines after AMI augments the neointimal hyperplasia of a remote artery ${ }^{22}$. However, the augmentation of neointimal hyperplasia of non-culprit coronary arteries in patients after AMI has not been investigated in detail.

The present study evaluates the progression of luminal narrowing among non-culprit coronary arteries in patients after AMI.

\section{Subjects and Methods}

\section{Subjects}

We examined consecutive patients with AMI and SA who underwent initial coronary angiography, were successfully treated by stent implantation for significant coronary artery stenosis $(>75 \%$ luminal narrowing), and were assessed by 6-month follow-up angiography between June 2004 and June 2005. Acute myocardial infarction was defined as typical chest pain at rest lasting $>30$ minutes accompanied by both STsegment and/or T-wave elevation on electrocardiography (ECG), elevation of creatine kinase to twice the upper normal limit, and positive response of the cardiac troponin $T$ rapid assay. Stable angina pectoris was defined as effort-related chest pain without any clinical changes in the preceding 2 months and negative cardiac troponin T. We performed PCI when indicated from the results of an exercise electrocardiography test and myocardial scintigraphy. We excluded the following patients to minimize the inflammatory response induced by stimulation other than AMI, SA, and the first coronary stenting procedure: (1) patients with in-hospital death after the primary procedure; (2) patients with AMI within 2 weeks of the primary procedure (to exclude potential subacute stent thrombosis of the treated arterial segment); (3) patients treated with a debulking device such as a rotablator or directional coronary atherectomy and (4) patients that underwent a second elective PCI, coronary artery bypass grafting, or other surgery within the 6-month follow-up period. We finally enrolled $21 \mathrm{AMI}$ and 16 SA patients in this study.

All of the enrolled patients were systematically administered both aspirin (81-100 mg/day) and ticlopidine $(200 \mathrm{mg} /$ day $)$. In the event of adverse reactions to ticlopidine, cilostazol $(150-200 \mathrm{mg} /$ day $)$ was prescribed instead. None of the patients was receiving hormone replacement therapy. There was no cardiac event in any of the patients throughout the study. This protocol was approved by our institutional ethics committee (\#2002-009), and was performed in accordance with the Helsinki Declaration of 1975.

\section{Coronary Risk Factors}

Peripheral venous blood samples were withdrawn from patients after at least a 12-h fast, in the morning, upon admission, and at 6-months follow-up to evaluate the following coronary risk factors: age, gender, body mass index (BMI), smoking habit, blood pressure $(\mathrm{BP})$, glycated hemoglobin $\mathrm{A} 1 \mathrm{c}(\mathrm{HbA} 1 \mathrm{c})$, triglyceride (TG), total cholesterol (T-Cho), high-density lipoprotein cholesterol (HDL-C), and low-density lipoprotein cholesterol (LDL-C). Levels of HbAlc were measured by high-performance liquid chromatography and those of TG, T-Cho, and HDL-C, by standard enzymatic methods. Levels of LDL-C were calculated using the Friedwald formula (T-cho-HDL-C TG/5), because TG concentrations were $<400 \mathrm{mg} / \mathrm{dL}$ in all patients. Hypertension was defined as repeated measurements $\geqq 140 \mathrm{mmHg}$ systolic $\mathrm{BP}$ and/or $\geqq 90$ $\mathrm{mmHg}$ diastolic BP and/or on permanent antihypertensive drug therapy. Dyslipidemia was defined as $\mathrm{TG} \geqq 150 \mathrm{mg} / \mathrm{dL}$ and/or HDL-C $<40 \mathrm{mg} / \mathrm{dL}$ and/or LDL-C $\geqq 140 \mathrm{mg} / \mathrm{dL}^{23)}$. Diabetes mellitus (DM) was defined as a fasting blood glucose concentration of $\geqq 126 \mathrm{mg} / \mathrm{dL}$ and/or HbAlc $\geqq 6.5 \%$ and/or receiving antihyperglycemic drug therapy.

In all patients, coronary risk factors were treated according to Japanease studies and guidelines ${ }^{24-26)}$. No restrictions were placed on the administration of medication.

\section{Inflammatory Markers}

Serial changes in inflammatory markers were determined in peripheral venous blood samples that were withdrawn from patients with AMI in the morning after at least a 12-h-fast. The white blood cell (WBC) count and the C-reactive protein (CRP) concentration were measured everyday until they reached peak values after stent implantation, using an automated hematology analyzer and an automated latex immunoturbidimetric assay, respectively. The WBC counts and CRP concentrations in the SA patients determined at the 
first day after stent implantation were defined as the peak values respectively, when within normal ranges.

\section{Cardiac Function}

B-type natriuretic peptide (BNP) was measured and echocardiography was performed at 6-months of follow-up, to evaluate cardiac function. Venous plasma BNP concentrations were measured using a radioimmunoassay (Shionoria BNP kit, Shionogi Co Ltd, Osaka, Japan). Echocardiograms were obtained using an ACUSON Sequoia Ultrasound Imaging System (Siemens, Erlangen, Germany). Ejection fraction (EF) was calculated using the modified Sympson's rule ${ }^{27)}$.

\section{Quantitative Coronary Angiography}

We used the Judkins percutaneous femoral artery approach technique for coronary angiography. Multiple views of the right and left coronary arteries were routinely recorded on a full digital imaging system equipped with a flat-panel detector (AXIOM Artis FC/BC, Siemens, Erlangen, Germany; Allura Xper FD10, Philips, Eindhoven, the Netherlands). Angiographic images were obtained after the administration of $200 \mu \mathrm{g}$ of intracoronary nitroglycerine.

Quantitative coronary angiographic (QCA) analysis was performed by a trained observer blind to the clinical background of subjects, using QCA-CMS software (MEDIS Medical Imaging Systems, Leiden, The Netherlands), in which coronary lumen diameters were measured using an automated edge-contour detection system. We evaluated both culprit and non-culprit coronary arteries. A culprit coronary artery was determined from ECG and echocardiographic findings, and the presence of stenosis and residual thrombosis in the artery. Non-culprit coronary arteries were defined as two coronary arteries (excluding the stented culprit coronary artery), and were limited to the proximal and mid coronary segments (AHA \#1, 2, 3, 6, $7,11,12,13)$. Angiographic images before (pre-procedure) and immediately after (post-procedure) stent implantation, as well as at the 6-month follow-up (chronic phase) were selected in the same view to clearly visualize narrowed lesions.

The lengths of the lesions were calibrated based on the image of the contrast-filled guiding catheter. The reference diameter $(\mathrm{mm})$, minimal lumen diameter (MLD) (mm), and diametric stenosis (\%) were measured in each segment of the culprit and non-culprit coronary arteries. The diametric stenosis was defined as [(reference diameter-MLD)/reference diameter $] \times 100$. The diameter gained by treatment (acute gain $=$ post - procedure MLD - pre-procedure MLD) $(\mathrm{mm})$ and the luminal loss in the chronic phase (late
Table 1. Patient characteristics (baseline)

\begin{tabular}{lccr}
\hline & $\begin{array}{c}\text { AMI } \\
(n=21)\end{array}$ & $\begin{array}{c}\text { Stable angina } \\
(n=16)\end{array}$ & $p$ value \\
\hline Age (years) & $64.2 \pm 11.1$ & $66.8 \pm 10.1$ & 0.47 \\
Men & $17(80.9 \%)$ & $6(37.5 \%)$ & $<0.01$ \\
BMI $\left(\mathrm{kg} / \mathrm{m}^{2}\right)$ & $23.8 \pm 2.6$ & $23.8 \pm 2.5$ & 0.99 \\
Past and current smoking & $16(76.1 \%)$ & $9(56.2 \%)$ & 0.19 \\
Hypertension & $10(47.6 \%)$ & $14(87.5 \%)$ & $<0.05$ \\
Dyslipidemia & $15(71.4 \%)$ & $13(81.2 \%)$ & 0.27 \\
Diabetes mellitus & $8(38.0 \%)$ & $6(37.5 \%)$ & 0.97 \\
\hline
\end{tabular}

Values are presented as means \pm standard deviations.

$\mathrm{AMI}=$ acute myocardial infarction, $\mathrm{BMI}=$ body mass index .

loss = post-procedure MLD - chronic phase MLD) $(\mathrm{mm})$ were determined in the culprit coronary artery. We also determined the absolute change in MLD $(\mathrm{mm})$ and diametric stenosis (\%) between pre-procedure and chronic phase in the non-culprit coronary arteries. A coronary diametric stenosis of $>50 \%$ was considered clinically significant.

\section{Statistics}

Statistical analysis was performed using StatView 4.5 MDSU statistical software (Abacus Concept, Inc., Berkeley, CA, USA). Data are presented as the mean \pm standard deviation (SD). Continuous quantitative data were compared using a matched Student's $t$ test and discontinuous quantitative data were compared using the $\chi^{2}$ test. Correlations between continuous variables were determined using a linear regression analysis. Statistical significance was established when $p<0.05$.

\section{Results}

\section{Patient Characteristics}

The baseline clinical background, excluding gender and hypertension, did not significantly differ between the two groups (Table 1). The clinical background at 6-months of follow-up, excluding systolic BP and EF on echocardiograms, was also similar between the two groups, and coronary risk factors were controlled well (Table 2). Systolic BP was significantly lower in patients with AMI than with SA, probably because the EF was significantly lower, and treatment with a angiotensin-converting enzyme inhibitor was somewhat more frequent in those with AMI.

\section{Stenting Procedural Characteristics}

Table 3 shows that the patients with AMI were implanted with a total of 22 BMS (BX velocity stent, 6; Duraflex stent, 6; Penta stent, 4; Driver stent, 3; Zeta 
Table 2. Patient characteristics at 6-month follow-up

\begin{tabular}{lccr}
\hline & $\begin{array}{c}\text { AMI } \\
(n=21)\end{array}$ & $\begin{array}{c}\text { Stable angina } \\
(n=16)\end{array}$ & $p$ value \\
\hline Current smoking & $4(19.0 \%)$ & $2(12.5 \%)$ & 0.59 \\
Systolic BP (mmHg) & $120.5 \pm 14.2$ & $131.3 \pm 16.6$ & $<0.01$ \\
Diastolic BP (mmHg) & $68.5 \pm 6.9$ & $71.3 \pm 10.1$ & 0.32 \\
HbA1c (\%) & $5.5 \pm 0.63$ & $5.6 \pm 0.70$ & 0.76 \\
TG (mg/dL) & $130.5 \pm 59.2$ & $102.9 \pm 29.8$ & 0.097 \\
T-Cho (mg/dL) & $194.7 \pm 35.5$ & $198.8 \pm 42.3$ & 0.74 \\
HDL-C (mg/dL) & $52.8 \pm 16.0$ & $59.6 \pm 16.5$ & 0.22 \\
LDL-C (mg/dL) & $115.0 \pm 30.7$ & $115.2 \pm 32.6$ & 0.98 \\
BNP (pg/mL) & $95.9 \pm 191.7$ & $59.2 \pm 68.2$ & 0.48 \\
Echocardiogram-EF (\%) & $55.9 \pm 10.4$ & $68.6 \pm 6.5$ & $<0.001$ \\
Medication & & & \\
$\quad$ ACE inhibitor & $10(47.6 \%)$ & $3(18.7 \%)$ & 0.068 \\
ARB & $9(42.8 \%)$ & $7(43.7 \%)$ & 0.95 \\
Statin & $12(57.1 \%)$ & $11(68.7 \%)$ & 0.47 \\
Fibrate & $1(4.7 \%)$ & $0(0 \%)$ & 0.37 \\
$\alpha$-glucosidase inhibitor & $3(14.2 \%)$ & $3(18.7 \%)$ & 0.66 \\
Pioglitazone & $0(0 \%)$ & $1(6.2 \%)$ & 0.24 \\
\hline
\end{tabular}

Values are presented as means \pm standard deviations.

$\mathrm{AMI}=$ acute myocardial infarction, $\mathrm{BP}=$ blood pressure, $\mathrm{HbA1} \mathrm{c}=$ glycated hemoglobin A1c, TG = triglyceride, $\mathrm{T}-\mathrm{Cho}=$ total cholesterol, HDL-C $=$ high-density lipoprotein cholesterol, LDL-C $=$ low-density lipoprotein cholesterol, $\mathrm{BNP}=$ brain natriuretic peptide, $\mathrm{ACE}=$ angiotensin-converting enzyme, $\mathrm{ARB}=$ angiotensin II receptor blocker.

Table 3. Characteristics of stenting procedures

\begin{tabular}{lccc}
\hline & $\begin{array}{c}\text { AMI } \\
(n=21)\end{array}$ & $\begin{array}{c}\text { Stable angina } \\
(n=16)\end{array}$ & $p$ value \\
\hline Total stent number & 22 & 21 & \\
Stent type & & & \\
$\quad$ Cypher & 0 & 21 & \\
$\quad$ BX velocity & 6 & 0 & \\
$\quad$ Duraflex & 6 & 0 & \\
$\quad$ Penta & 3 & 0 & \\
$\quad$ Driver & 2 & 0 & \\
Zeta & 1 & 0 & \\
$\quad$ S670 & $3.29 \pm 0.42$ & $2.82 \pm 0.37$ & $<0.001$ \\
Stent diameter (mm) & $18.1 \pm 4.9$ & $19.3 \pm 3.4$ & 0.38 \\
Stent length (mm) & $16.0 \pm 4.6$ & $16.4 \pm 3.58$ & 0.75 \\
Pressure (atm) & & & \\
Inflammation after PCI & $12.1 \pm 2.8$ & $6.1 \pm 2.0$ & $<0.0001$ \\
$\quad \begin{array}{l}\text { Peak WBC count } \\
\left(\times 10^{3} / \mu \text { L) }\right.\end{array}$ & $8.8 \pm 5.3$ & $0.8 \pm 1.5$ & $<0.0001$ \\
$\begin{array}{l}\text { Peak CRP concentration } \\
(\text { mg/dL) }\end{array}$ & & & \\
\hline
\end{tabular}

Values are presented as means \pm standard deviations.

$\mathrm{AMI}=$ acute myocardial infarction, $\mathrm{PCI}=$ percutaneous coronary intervention, $\mathrm{WBC}=$ white blood cell, $\mathrm{CRP}=\mathrm{C}$-reactive protein.
Table 4. Angiographic data for culprit lesions

\begin{tabular}{lccc}
\hline & $\begin{array}{c}\text { AMI } \\
(n=21)\end{array}$ & $\begin{array}{c}\text { Stable angina } \\
(n=16)\end{array}$ & $p$ value \\
\hline Number of coronary artery stenoses & & \\
1 vessel & $19(90.4 \%)$ & $12(75.0 \%)$ & 0.40 \\
2 vessels & $2(9.6 \%)$ & $4(25.0 \%)$ & \\
Location of stented coronary artery & & \\
LAD & 12 & 13 & \\
LCX & 1 & 3 & 0.33 \\
RCA & 9 & 5 & \\
Reference diameter (mm) & $3.02 \pm 0.59$ & $2.20 \pm 0.31$ & $<0.0001$ \\
MLD (mm) & & & \\
Pre-procedure & $0.35 \pm 0.48$ & $0.92 \pm 0.66$ & $<0.01$ \\
Post-procedure & $2.90 \pm 0.59$ & $2.81 \pm 0.31$ & 0.56 \\
Chronic phase & $1.96 \pm 0.78$ & $2.57 \pm 0.35$ & $<0.01$ \\
Acute gain & $2.55 \pm 0.69$ & $1.89 \pm 0.66$ & $<0.01$ \\
Late loss & $0.94 \pm 0.67$ & $0.24 \pm 0.35$ & $<0.001$ \\
Diametric stenosis (\%) & & & \\
Pre-procedure & $86.9 \pm 16.7$ & $63.8 \pm 16.5$ & $<0.0001$ \\
Post-procedure & $10.9 \pm 8.0$ & $10.4 \pm 5.3$ & 0.8124 \\
Chronic phase & $31.7 \pm 21.5$ & $9.6 \pm 5.4$ & $<0.001$ \\
\hline Ply & & &
\end{tabular}

Values are presented as means \pm standard deviations.

$\mathrm{AMI}=$ acute myocardial infarction, $\mathrm{LAD}=$ left anterior descending artery, $\mathrm{LCX}=$ left circumflex artery, $\mathrm{RCA}=$ right coronary artery, $\mathrm{MLD}=$ minimal lumen diameter

stent, 2; s670 stent, 1), and those with SA were implanted with a total of 21 SES. The procedural characteristics, excluding stent diameter, were similar between the two groups. Peak WBC counts and peak CRP concentrations after PCI were significantly higher in the AMI than SA group $(p<0.0001, p<0.0001$, respectively). Peak WBC counts and peak CRP concentrations in the SA group were within the normal ranges.

\section{Coronary Artery Characteristics Culprit Coronary Arteries}

Table 4 shows the angiographic findings of culprit coronary arteries. The number of coronary artery stenoses and the location of stented coronary arteries were similar between the two groups. Most patients had single vessel stenosis because those with multivessel stenosis underwent elective PCI or coronary artery bypass grafting, and were excluded from the present study. The reference diameter was significantly larger in the AMI than SA group (3.02 \pm 0.59 vs. $2.20 \pm 0.31$, $p<0.0001$ ), and pre-procedure MLD was significantly smaller in the AMI group $(0.35 \pm 0.48$ vs. $0.92 \pm 0.66$, $p<0.01)$. Post-procedure MLD was sufficiently large in both the groups, and did not significantly differ 
Table 5. Angiographic data for non-culprit lesions

\begin{tabular}{|c|c|c|c|}
\hline & $\begin{array}{c}\text { AMI } \\
(n=21)\end{array}$ & $\begin{array}{l}\text { Stable angina } \\
\quad(n=16)\end{array}$ & $p$ value \\
\hline Total number of segments & 73 & 53 & \\
\hline \multicolumn{4}{|l|}{$\operatorname{MLD}(\mathrm{mm})$} \\
\hline Pre-procedure & $2.61 \pm 0.78$ & $2.02 \pm 0.56$ & $<0.0001$ \\
\hline Chronic phase & $2.44 \pm 0.71$ & $2.03 \pm 0.50$ & $<0.001$ \\
\hline Absolute change & $0.17 \pm 0.53$ & $0.0070 \pm 0.26$ & $<0.05$ \\
\hline \multicolumn{4}{|l|}{ Diametric stenosis (\%) } \\
\hline Pre-procedure & $19.3 \pm 12.1$ & $27.9 \pm 11.7$ & $<0.0001$ \\
\hline Chronic phase & $23.4 \pm 14.9$ & $23.1 \pm 10.9$ & 0.92 \\
\hline Absolute change & $4.85 \pm 18.9$ & $1.58 \pm 15.0$ & $<0.05$ \\
\hline
\end{tabular}

Values are presented as means \pm standard deviations.

$\mathrm{AMI}=$ acute myocardial infarction, $\mathrm{MLD}=$ minimal lumen diameter.

between them $(2.90 \pm 0.59$ vs. $2.81 \pm 0.31, p=0.56)$. Chronic phase MLD was significantly smaller in the AMI than SA group $(1.96 \pm 0.78$ vs. $2.57 \pm 0.35, p<$ 0.01 ), and late loss was significantly larger in the AMI group $(0.94 \pm 0.67$ vs. $0.24 \pm 0.35, p<0.001)$.

\section{Non-Culprit Coronary Arteries}

Table 5 shows the angiographic findings of 126 non-culprit coronary segments (AMI, 73 segments; SA, 53 segments). Pre-procedure MLD (mm) was significantly larger in the AMI than SA group $(2.61 \pm 0.78$ vs. $2.02 \pm 0.56, p<0.0001)$. At the 6 -month follow-up, the decrease in MLD was more frequent in the AMI (42 segments, 57.5\%) than SA (25 segments, 47.1\%) group. The frequency of an MLD decrease per patient was greater in the AMI $(54.2 \pm 31.7 \%)$ than SA (44.0 $\pm 36.1 \%$ ) group, although this difference was not significant. The MLD ( $\mathrm{mm}$ ) decreased significantly from $2.61 \pm 0.79$ to $2.44 \pm 0.71$ in patients with AMI $(p<$ 0.01 ), but changed only slightly from $2.02 \pm 0.56$ to $2.02 \pm 0.50$ in SA patients $(p=0.84)$. The absolute change $(\mathrm{mm})$ in MLD between pre-procedure and the chronic phase was significantly greater in the AMI than the SA group $(0.17 \pm 0.53$ vs. $0.0070 \pm 0.26, p<0.05)$.

Neither peak WBC count, peak CRP concentration, TG, T-Cho, HDL-C, nor LDL-C correlated with the MLD decrease in each group.

\section{Discussion}

\section{Culprit Lesions}

The reference diameter of the culprit lesion was significantly larger in the AMI than SA group, which is consistent with the findings of Hong et al. ${ }^{28)}$. Late loss $(\mathrm{mm})$ was $0.94 \pm 0.67$ after BMS implantation in the AMI group, and $0.24 \pm 0.35$ after SES implanta- tion in the SA group. These findings were compatible with those of others ${ }^{5-10}$ ) and support the accuracy of the QCA used in the present study.

\section{Non-Culprit Lesions}

The present results support the notion that the activation of proinflammatory cytokines after AMI augments the neointimal hyperplasia of remote arteries. In patients with AMI whose WBC count and CRP concentration were elevated, the MLD $(\mathrm{mm})$ of nonculprit coronary arteries significantly decreased from $2.61 \pm 0.79$ to $2.44 \pm 0.71$ within 6 months after stent implantation $(p<0.01)$, whereas the change was minimal in SA patients without such elevations (from 2.02 \pm 0.56 to $2.02 \pm 0.50 ; p=0.84$ )

We used the WBC count and CRP concentration as inflammatory markers because of the absence of surplus blood samples, although we previously reported that activated TNF- $\alpha$ and IL- 6 augment neointimal hyperplasia ${ }^{22)}$. Hasegawa et al. reported that the WBC count is closely related to other conventional coronary risk factors and is an important indicator of chronic inflammation ${ }^{29)}$. The CRP concentration becomes elevated after balloon angioplasty ${ }^{30)}$ and stent implantation ${ }^{31)}$, and predicts in-stent restenosis within 12-months follow-up ${ }^{32)}$. Therefore, the WBC count and the CRP concentration are considered appropriate for evaluating inflammation after AMI. Hong et al. compared coronary plaque rupture between AMI and SA using three-vessel intravascular ultrasound ${ }^{28)}$, and reported that both non-culprit and culprit coronary plaque rupture are more frequent in patients with AMI than with SA. Plaque rupture in AMI patients was associated with a high CRP concentration, whereas that in SA patients was associated with diabetes. These findings are consistent with those of the present study, suggesting that inflammation after AMI increases the vulnerability of non-culprit arteries to atheromatous plaques. Despite the reduction in in-stent restenosis rates by SES, this does not demonstrate an improvement of long-term progno$\operatorname{sis}^{10,12)}$. One cause of this discrepancy might be the progression of atherosclerosis in non-culprit arteries. For the reasons stated above, careful management of non-culprit coronary arteries is critical to further improve the long-term prognosis of patients with AMI.

In contrast, systemic effects of the elution of sirolimus remain controversial. An implanted SES was reportedly associated with exercise-induced paradoxical coronary vasoconstriction of the adjacent vessel segments ${ }^{33)}$. Furthermore, the implantation of SES suppressed, whereas the implantation of BMS induced, the mobilization and differentiation into both smooth 
muscle-like and endothelium-like cells of bone marrow cells, possibly leading to restenosis ${ }^{34)}$. However, the reported peak sirolimus concentration after SES implantation is approximately $0.86-2.00 \mathrm{ng} / \mathrm{mL}$, far lower than the effective concentration when sirolimus is orally administered as an immunosuppressive agent ${ }^{35)}$.

In the present study, SA patients received SES, and AMI patients received BMS. Therefore, systemic effects after SES implantation might have inhibited atherosclerosis in non-culprit coronary arteries.

\section{Study Limitations}

The present study has four potential limitations. First, we retrospectively analyzed a relatively small sample of patients. Second, we routinely use $4 \mathrm{~F}$ coronary catheters for coronary angiography to minimize the invasive effect on patients. The use of small catheters as a calibration standard may induce measurement bias for QCA. Third, QCA cannot clarify the cause of luminal narrowing in non-culprit coronary arteries. Ehara et al. reported that plaque morphology and pathology are closely related to progression characteristics $^{18)}$. Fourth, we used the peak WBC count and peak CRP concentration as inflammatory markers, although they are non-specific in this context. Moreover, we could not calculate the area under the curve (AUC) for these markers. Thus, we could indicate that the inflammation is related to the progression of non-culprit coronary artery atherosclerosis, but could not clarify whether the degree of inflammation is related to the progression and/or severity of the atherosclerosis.

Finally, our results should be confirmed by further prospective studies with large cohorts using specific inflammatory markers and other imaging methods, such as coronary computed tomography, cardiac magnetic resonance imaging, intravascular ultrasound (IVUS), and optical coherence tomography (OCT).

\section{Conclusion}

Within 6 months of stent implantation, luminal narrowing of non-culprit coronary segments had clearly progressed in patients with AMI, but progressed minimally in patients with SA.

\section{Acknowledgments and Notice of Grant Support}

None to declare.

\section{References}

1) Gruntzig AR, Senning A, and Siegenthaler WE: Nonop- erative dilatation of coronary -artery stenosis: percutaneous transluminal coronary angioplasty. N Engl J Med, 1979; 301:61-68

2) Gruentzig AR, King SB 3rd, Schlumpf M, and Siegenthaler W: Long-term follow-up after percutaneous transluminal coronary angioplasty. The early zurich experience. $\mathrm{N}$ Engl J Med, 1987; 316:1127-1132

3) Simpfendorfer C, Belardi J, Bellamy G, Galan K, Franco I, and Hollman J: Frequency, management and follow-up of patients with acute coronary occlusion after percutaneous transluminal coronary angioplasty. Am J Cardiol, 1987; 59:267-269

4) Nobuyoshi M, Kimura T, Nosaka H, Mioka S, Ueno K, Yokoi H, Hamasaki N, Horiuchi H, and Ohishi H: Restenosis after successful percutaneous transluminal coronary angioplasty: serial angiographic follow-up of 229 patients. J Am Coll Cardiol, 1988; 12:616-623

5) Fischman DL, Leon MB, Baim DS, Schatz RA, Savage MP, Penn I, Detre K, Veltri L, Ricci D, Nobuyoshi M, Cleman M, Heuser R, Almond D, Teirstein PS, Fish RD, Colombo A, Brinker J, Moses J, Shaknovich A, Hirshfeld J, Bailey S, Ellis S, Ranke R, and Goldberg S: A randomized comparison of coronary-stent placement and balloon angioplasty in the treatment of coronary artery disease. Stent Restenosis Study Investigators. N Engl J Med, 1994; 331:496-501

6) Serruys PW, de Jaegere P, Kiemeneij F, Macaya C, Rutsch W, Heyndrickx G, Emanuelsson H, Marco J, Legrand V, Materne P, Belardi J, Sigwart U, Colombo A, Goy JJ, Heuvel PVD, Delcan J, and Morel MA: A comparison of balloon-expandable-stent implantation with balloon angioplasty in patients with coronary artery disease. Benestent Study Group. N Engl J Med, 1994; 331:489-495

7) Schömig A, Neumann FJ, Kastrati A, Schühlen H, Blasini R, Hadamitzky M, Walter H, Zitzmann-Roth EM, Richardt G, Alt E, Schmitt C, and Ulm K: A randomized comparison of antiplatelet and anticoagulant therapy after the placement of coronary-artery stents. N Engl J Med, 1996; 334:1084-1089

8) Leon MB, Baim DS, Popma JJ, Gordon PC, Cutlip DE, Ho KK, Giambartolomei A, Diver DJ, Lasorda DM, Williams DO, Pocock SJ, and Kuntz RE: A clinical trial comparing three antithrombotic-drug regimens after coronaryartery stenting. Stent Anticoagulation Restenosis Study Investigators. N Engl J Med, 1998; 339:1665-1671

9) Moses JW, Leon MB, Popma JJ, Fitzgerald PJ, Holmes DR, O'Shaughnessy C, Caputo RP, Kereiakes DJ, Williams DO, Teirstein PS, Jaeger JL, and Kuntz RE: SIRIUS Investigators. Sirolimus-eluting stents versus standard stents in patients with stenosis in a native coronary artery. N Engl J Med, 2003; 349:1315-1323

10) Morice MC, Serruys PW, Sousa JE, Fajadet J, Ban Hayashi E, Perin M, Colombo A, Schuler G, Barragan P, Guagliumi G, Molnàr F, and Falotico R: RAVEL Study Group. Randomized Study with the Sirolimus-Coated Bx Velocity Balloon-Expandable Stent in the Treatment of Patients with de Novo Native Coronary Artery Lesions. A randomized comparison of a sirolimus-eluting stent with a standard stent for coronary revascularization. N Engl J Med, 2002; 346:1773-1780 
11) McFadden EP, Stabile E, Regar E, Cheneau E, Ong AT, Kinnaird T, Suddath WO, Weissman NJ, Torguson R, Kent KM, Pichard AD, Satler LF, Waksman R, and Serruys PW: Late thrombosis in drug-eluting coronary stents after discontinuation of antiplatelet therapy. Lancet, 2004; 364:1519-1521

12) Stone GW, Moses JW, Ellis SG, Schofer J, Dawkins KD, Morice MC, Colombo A, Schampaert E, Grube E, Kirtane AJ, Cutlip DE, Fahy M, Pocock SJ, Mehran R, and Leon MB: Safety and efficacy of sirolimus- and paclitaxel-eluting coronary stents. N Engl J Med, 2007; 356:1059-1060

13) Hon-Kan Yip, Pei-wen Wang, Li-Teh Chang, Ali A. Youssef, Jiunn-Jye Sheu, Fan-Yen Lee, and Chiung-Jen Wu: Cytotoxic $\mathrm{T}$ lymphocyte antigen 4 gene polymorphism associated with ST-segment elevation acute myocardial infarction. Circ J, 2007; 71:1213-1218

14) Wojakowski W, Maslankiewicz K, Ochala A, Wyderka R, Zuk-Popiolek I, Flak Z, Mroz I, and Tendera M: The proand anti-inflammatory markers in patients with acute myocardial infarction and chronic stable angina. Int J Mol Med, 2004; 14:317-322

15) Ashida K, Miyazaki K, Takayama E, Tsujimoto H, Ayaori $\mathrm{M}$, Yakushiji T, Iwamoto $\mathrm{N}$, Yonemura A, Isoda $\mathrm{K}$, Mochizuki H, Hiraide H, Kusuhara M, and Ohsuzu F: Characterization of the expression of TLR2 (toll-like receptor 2) and TLR4 on circulating monocytes in coronary artery disease. J Atheroscler Thromb, 2005; 12:53-60

16) Zhou RH, Shi Q, Gao HQ, and Shen BJ: Changes in serum interleukin-8 and interleukin-12 levels in patients with ischemic heart disease in a Chinese population. J Atheroscler Thromb, 2001; 8:30-32

17) Kawamura A, Miura $S$, Murayama $T$, Iwata $A$, Nishikawa H, Matsuo Y, Tsuchiya Y, Matsuo K, Tsuji E, and Saku K: Changes in the expression of leukocyte adhesion molecules throughout the acute phase of myocardial infarction. J Atheroscler Thromb, 2004; 11:29-34

18) Ehara S, Kobayashi Y, Yoshiyama M, Ueda M, and Yoshikawa J: Coronary artery calcification revisited. J Atheroscler Thromb, 2006; 13:31-37

19) Chen L, Chester MR, Crook R, and Kaski JC: Differential progression of complex culprit stenoses in patients with stable and unstable angina pectoris. J Am Coll Cardiol, 1996; 28:597-603

20) Frangogiannis NG, Smith CW, and Entman ML: The inflammatory response in myocardial infarction. Cardiovasc Res, 2002; 53:31-47

21) Aoki M, Morishita R, Taniyama Y, Kaneda Y, and Ogihara $\mathrm{T}$ : Therapeutic angiogenesis induced by hepatocyte growth factor: potential gene therapy for ischemic diseases. J Atheroscler Thromb, 2000; 7:71-76

22) Takaoka M, Uemura S, Kawata H, Imagawa K, Takeda $Y$, Nkatani K, Naya N, Horii M, Yamano S, Miyamoto Y, Yoshimasa Y, and Saito Y: Inflammatory response to acute myocardial infarction augments neointimal hyperplasia after vascular injury in a remote artery. Arterioscler Thromb Vasc Biol, 2006; 26:2083-2089

23) Teramoto T, Sasaki J, Ueshima H, Egusa G, Kinoshita M, Shimamoto K, Daida H, Biro S, Hirobe K, Funahashi T, Yokote $\mathrm{K}$, and Yokode M; Japan Atherosclerosis Society (JAS). Committee for Epidemiology and clinical Manage- ment of Atherosclerosis: Diagnostic criteria for dyslipidemia. Executive summary of Japan Atherosclerosis Society (JAS) guideline for diagnosis and prevention of atherosclerotic cardiovascular diseases for Japanese. J Atheroscler Thromb, 2007; 14:155-158

24) Kinoshita M, Ishikawa $K$, Inoue $H$, Sakakibara $H$, Kanmatsuse K, Saito Y, Nonogi H, Hiramori K, Suzuki T, Nakamura Y, Katagiri T, Shirato K, Fujita M, Maruyama Y, and Miura M: Guidelines for secondary prevention of myocardial infarction. Jpn Circ J, 2000; 65 Supple. IV:863867

25) Saito Y, Shirai K, Sasaki N, Shinomiya M, and Yoshida S: Prognosis of hypercholesterolemic patients taking pravastatin for five years: The Chiba lipid intervention program (CLIP) study. J Atheroscler Thromb, 2002; 9:99-108

26) Koizumi J, Shimizu M, Miyamoto S, Origasa H, and Mabuchi H: Effect of pravastatin-induced LDL-cholesterol reduction on coronary heart disease and cerebrovascular disease in Japanese: Hokuriku lipid coronary heart disease study-pravastatin atherosclerosis trial (Holicos-PAT). J Atheroscler Thromb, 2002; 9:251-259

27) Parisi AF, Moynihan PF, Feldman CL, and Folland ED: Approaches to determination of left ventricular volume and ejection fraction by real-time two-dimensional echocardiography. Clin Cardiol, 1979; 2:257-263

28) Hong MK, Mintz GS, Lee CW, Kim YH, Lee SW, Song JM, Han KH, Kang DH, Song JK, Kim JJ, Park SW, and Park SJ: Comparison of coronary plaque rupture between stable angina and acute myocardial infarction: A threevessel intravascular ultrasound study in 235 patients. Circulation, 2004; 110:928-933

29) Hasegawa T, Negishi T, and Deguchi M: WBC count, atherosclerosis and coronary risk factors. J Atheroscler Thromb, 2002; 9:219-223

30) Azar RR, McKay RG, Kiernan FJ, Seecharran B, Feng YJ, Fram DB, Wu AH, and Waters DD: Coronary angioplasty induces a systemic inflammatory response. Am J Cardiol, 1997; 80:1476-1478

31) Gaspardone A, Crea F, Versaci F, Tomai F, Pellegrino A, Chiariello L, and Gioffré PA: Predictive value of C-reactive protein after successful coronary-artery stenting in patients with stable angina. Am J Cardiol, 1998; 82:515-518

32) Angioi M, Abdelmouttaleb I, Rodriguez RM, AimoneGastin I, Adjalla C, Guéant JL, and Danchin N: Increased $\mathrm{C}$-reactive protein levels in patients with in-stent restenosis and its implications. Am J Cardiol, 2001; 87:1189-1193

33) Togni M, Windecker $S$, Cocchia R, Wenaweser P, Cook $S$, Billinger M, Meier B, and Hess OM: Sirolimus-eluting stents associated with paradoxic coronary vasoconstriction. J Am Coll Cardiol, 2005; 46:231-236

34) Inoue $T$, Sata M, Hikichi $Y$, Sohma R, Fukuda D, Uchida T, Shimizu M, Komoda H, and Node K: Mobilization of CD34-positive bone marrow-derived cells after coronary stent implantation. Impact on restenosis. Circulation, 2007; 115:553-561

35) Otsuka Y, Nakamura M, Yasuda S, Kozuma K, Hara H, Morii I, Kawamura A, Sase K, and Miyazaki S: Comparison of pharmacokinetics of the sirolimus-eluting stent in Japanese patients with those in American patients. J Cardiovasc Pharmacol, 2005; 46:468-473 